\title{
Inverted and Impacted Third Molar
}

\author{
Ramesh Chandra ${ }^{1}$, Ambrish Kaushal ${ }^{2}$
}

\begin{abstract}
A case of unilateral impacted and inverted third molar has been reported. Its management should be performed in the conservative way to avoid conservative way to avoid serious consequences.
\end{abstract}

Keywords: Inverted, Impacted, Third molar

${ }^{1}$ Reader

Department of Conservative Dentistry and Endodontics

Career Post Graduate Institute of Dental

Sciences, Lucknow

${ }^{2}$ Senior Lecturer

Department of Oral Pathology

Career Post Graduate Institute of Dental

Sciences, Lucknow

\section{Contact Autbor \\ Dr. Ramesh Chandra dr.rameshchandra01@gmail.com \\ J Oral Health Comm Dent 2011;5(2)56-57}

\section{INTRODUCTION}

1

$n$ impacted tooth is one which is prevented from its normal path of eruption in the dental arch due to lack of space in the arch or obstruction in the eruptive pathway of the tooth. Impacted teeth may therefore be nonfunctional, abnormal or pathological or the level of impaction can be determined using Pell and Gregory classification as follows (1-4):

- Position A: The highest portion of mandibular third molar is on a level with or above the occlusal plane.

- Position B: The highest portion of impacted third molar is below the occlusal plane but above the cervical line of the second mandibular molar.

- Position C: The highest portion of impacted mandibular third molar is below the cervical line of the second mandibular molar.

- Position I: None of the crown is in the ramus of the mandible
- Position II: Less than half of the crown is in the ramus of mandible

- Position III: More than half of the crown is in the ramus.

Maxillary and mandibular third molars as well as maxillary cuspids are the most frequently impacted teeth. A very few cases of inverted and impacted third molars have been reported in the literature. This case report describes a case of inverted and impacted unilateral mandibular third molar.

\section{CASE REPORT}

A 52 year old male patient reported to dental clinic complaining of pain and difficulty in opening mouth. He pointed out regarding the pain in the mandibular right posterior region. An OPG was taken and it showed an inverted mandibular third molar on the right side. It also showed a horizontal impaction of mandibular left third molar for which the patient has been informed but he refused for the removal of impactions (Figure 1).

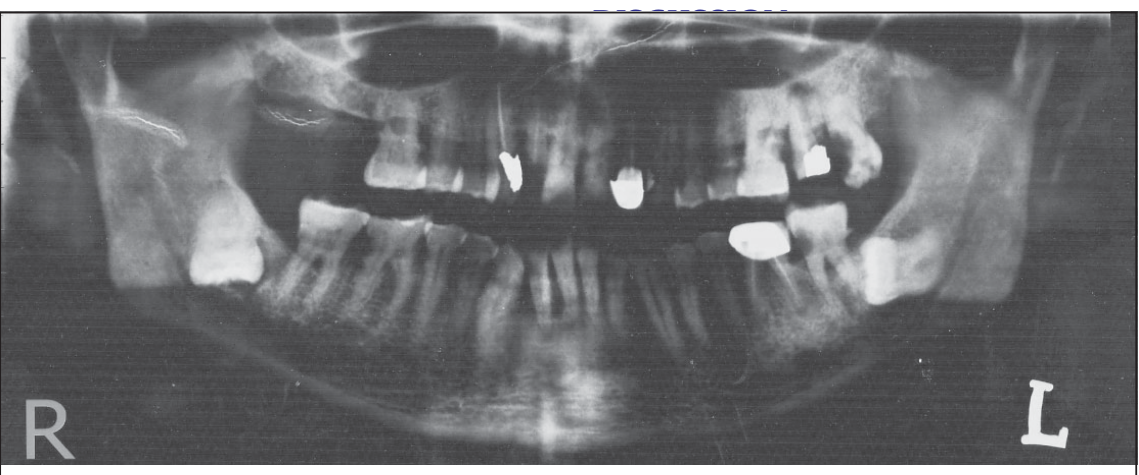

Figure 1: An OPG showing an inverted mandibular third molar on the right side 
Third molars in both the mandible and maxilla may develop far from their normal location due to unusual proliferation of Odontogenic epithelium before development of tooth germ. ${ }^{1}$ The inverted impaction has been called a complicated impaction as it has a crown pointing downwards and root pointing towards the alveolar crest. ${ }^{3}$ In literature there is limited knowledge about the presence of unusual or multiple unerupted molars. Systemic factors such as cleidocranial dysplasia, endocrine deficiency, febrile disease, Down syndrome and irradiation, other systemic factors or/and local factors such as prolonged decidous tooth retention, malposed tooth germs, arch length deficiency, supernumerary teeth,
Odontogenic tumors, abnormal eruptive pathway, cleft lip/palate may influence impaction of permanent teeth. ${ }^{2}$

Removal of an inverted tooth is more complicated than that of simply impacted tooth because of age of the patient and the deeper position of the inverted tooth. Loss of bone would be a major disadvantage since these teeth are completely impacted in the bone. ${ }^{3}$ The dentist must weigh between risks and benefits of removal of impacted third molars and explain them thoroughly to the patient. The risk factors associated with surgical removal should be communicated to the patient. Patient's compliance or whether to or not to proceed must be obtained.

\section{REFERENCES}

1. Saleh M, Alshamrani. Inverted and impacted third molar-report of two cases. Odonto-Stomatologie Tropicale 2001; 15-17.

2. Karacayli U, Gocmen-Mas N. multiple abnormal unerupted mandibular permanent molar teeth- A case report. Int J Morphol 2009;27(1)65-68.

3. Pai V, kundabala M, Sequiera PS, Rao A. inverted and impacted maxillary and mandibular $3^{\text {rd }}$ molars; A very rare case. J Oral Health Comm Dent 2008;2(1)89.

4. Obiechina AE, Arotiba JT, Fasola AO. Third molar impaction: Evaluation of the symptoms and pattern of impaction of mandibular third molar teeth in Nigerians. Odonto-Stomatologie Tropicale 2001; 22-25. 